\title{
Assessing Commonality in Liquidity with Principal Component Analysis: The Case of the Warsaw Stock Exchange
}

\author{
Joanna Olbryśs ${ }^{1, *(D)}$ and Elżbieta Majewska ${ }^{2}$ (D) \\ 1 Faculty of Computer Science, Bialystok University of Technology, 15-351 Bialystok, Poland \\ 2 Faculty of Economics and Finance, University of Bialystok, 15-328 Bialystok, Poland; \\ e.majewska@uwb.edu.pl \\ * Correspondence: j.olbrys@pb.edu.pl
}

Received: 26 November 2020; Accepted: 18 December 2020; Published: 21 December 2020

\begin{abstract}
The studies concerning commonality in liquidity on emerging markets in Central and Eastern Europe are scarce and, in particular, they do not utilize the Principal Component Analysis (PCA) to identify latent factors in liquidity. Therefore, the main aim of this research is to assess commonality in liquidity on the Warsaw Stock Exchange (WSE) with the use of the PCA to extract common components of liquidity across a sample of stocks, and from a set of several liquidity proxies. The robustness tests within the whole sample and sub-periods are provided. The PCA results reveal that common latent factors in liquidity estimates exist on the Polish stock market, and three principal components are sufficient to substitute for the seven liquidity proxies utilized in this research. The regressions using these three principal components of liquidity proxies as latent factors in the market model of liquidity indicate no evidence of co-movements in liquidity on the WSE. The results are homogenous for all investigated periods so no reason has been found to reject the research hypothesis that commonality in liquidity does not exist on the Polish stock market. To the best of the authors' knowledge, no similar research has been conducted for the WSE thus far.
\end{abstract}

Keywords: market microstructure; high-frequency data; daily data; commonality in liquidity; PCA; GARCH; Warsaw Stock Exchange

\section{Introduction}

Growing interest in market microstructure is driven by the rapid structural, technological, and regulatory changes affecting the world financial industry (Madhavan 2000). Harris (2003) noted that market microstructure is the branch of financial economics that explores trading and the organization of markets. From the practitioner's point of view, it is especially important how various trading rules affect price efficiency, trading profits, and liquidity. Understanding liquidity should be one of the primary objectives of each investor. However, stock market liquidity is difficult to investigate as it is unobservable. Moreover, some researchers have emphasized that liquidity measures capture only noisy information about liquidity (Chen 2005). Since Chordia et al. (2000), researchers have shifted their focus from the assessment of liquidity of individual equities toward investigation of common components and determinants of liquidity across securities.

According to the literature, the Principal Component Analysis (PCA) has broad applications as it unveils simple underlying structures in complex data sets utilizing analytical solutions from linear algebra. It can be utilized to extract common features of a set of economic variables. Therefore, one possible application of the PCA can be an extraction of latent factors from a set of liquidity measures across securities on equity markets (Hasbrouck and Seppi 2001; Chen 2005; Korajczyk and Sadka 2008; Foran et al. 2015). 
Generally, the studies concerning commonality in liquidity on emerging markets in Central and Eastern Europe are scarce and, in particular, they do not utilize the PCA to identify latent factors in liquidity. For instance, Olbryś (2020) explored six small Central and Eastern European (CEE) stock markets in the Czech Republic, Hungary, Slovakia, Lithuania, Estonia, and Latvia using market liquidity models, and she found no reason to reject the research hypothesis concerning the absence of commonality in liquidity on each individual stock exchange. As for the Polish equity market, Będowska-Sójka (2019) and Olbryś (2019) thoroughly investigated commonality in liquidity on the Warsaw Stock Exchange (WSE) utilizing different econometric methods and various liquidity proxies, but they did not employ the PCA.

The proposed research hypothesis states that there is no commonality in liquidity on the WSE. Therefore, the main aim of this research, which is the continuation of the previous studies, is to assess co-movements in liquidity on the WSE using the PCA to extract common components of liquidity from a set of liquidity measures and across a sample of equities. The goal is to estimate latent factor models of liquidity, aggregated across various liquidity estimates (Foran et al. 2015; Korajczyk and Sadka 2008). The empirical results for the Polish equity market are novel and, to the best of the authors' knowledge, have not been discussed in the literature.

The remainder of the study is organized as follows. Section 2 specifies the methodological background of assessing commonality in liquidity. In Section 3, liquidity/illiquidity proxies utilized in this study are described in detail. Section 4 presents the PCA. Section 5 contains data description and presents the empirical results. In Section 6, we discuss the findings on the WSE compared to other stock markets in the world. The last section presents the conclusion and suggestions for further research.

\section{Commonality in Liquidity-Methodological Background}

The market model of liquidity introduced by Chordia et al. (2000) is the most frequently applied model in assessing commonality in liquidity. In this study, a modified version of this model, including the Dimson (1979) correction for daily data, was used:

$$
D L_{i, t}=\alpha_{i}+\beta_{i,-1} \cdot D L_{M, t-1}+\beta_{i, 0} \cdot D L_{M, t}+\beta_{i,+1} \cdot D L_{M, t+1}+\varepsilon_{i, t}
$$

where $D L_{i, t}$ for stock $i$ is the change in liquidity variable $L$ from trading day $t-1$ to $t$, i.e., $D L_{t}=\frac{L_{t}-L_{t-1}}{L_{t-1}}$. The Dimson correction allowed us to mitigate the non-synchronous trading problem. In this procedure, three explanatory variables were included in the model equation. These variables are the lagged $\left(D L_{M, t-1}\right)$, concurrent $\left(D L_{M, t}\right)$, and leading $\left(D L_{M, t+1}\right)$ changes in a cross-sectional average of the liquidity variable $L$. The main idea is that in calculating the "market" liquidity proxy $L_{M}$, stock $i$ is excluded and the measure $L_{M}$ is estimated as the equally weighted average liquidity for the remaining stocks. Therefore, the explanatory variables in the model (1) are slightly different for each stock regression. It is crucial that positive and statistically significant coefficients $\beta_{i, 0}, \beta_{i,-1}$, and $\beta_{i,+1}$ are especially desired since they indicate liquidity co-movements in the same direction (Brockman et al. 2009).

In the first step, model (1) was estimated for each stock by the Ordinary Least Squares (OLS) regression with the robust Heteroskedasticity and Autocorrelation Consistent Covariance Method (HAC) estimates (Newey and West 1987). However, the OLS-HAC method may not be fully correct for the influence problems caused by the Autoregressive Conditional Heteroskedasticity (ARCH) effect. In such cases, estimating model (1) as a Generalized Autoregressive Conditional Heteroskesticity (GARCH)-type model was more appropriate. Engle (1982) test with the Lagrange Multiplier (LM) statistic was used to infer the ARCH effect. The GARCH(p, q) model is given by Equation (2):

$$
\begin{gathered}
D L_{i, t}=\alpha_{i}+\beta_{i,-1} \cdot D L_{M, t-1}+\beta_{i, 0} \cdot D L_{M, t}+\beta_{i,+1} \cdot D L_{M, t+1}+\varepsilon_{i, t}, \\
\varepsilon_{i, t}=z_{i, t} \sqrt{\mathrm{h}_{\mathrm{i}, t}}, z_{i, t} \sim N(0,1), \\
\mathrm{h}_{\mathrm{i}, \mathrm{t}}=a_{i, 0}+\sum_{k=1}^{q} a_{i, k} \varepsilon_{i, t-k}^{2}+\sum_{l=1}^{p} b_{i, l} \mathrm{~h}_{\mathrm{i}, \mathrm{t}-\mathrm{l}}
\end{gathered}
$$


where $a_{i, 0}>0, a_{i, k} \geq 0, k=1, \ldots, q, q>0, b_{i, l} \geq 0, l=1, \ldots, p, p \geq 0$. The $\varepsilon_{i, t}$ is the innovation in a linear regression with $V(\varepsilon)=\sigma^{2}$, and $h_{i, t}$ is the variance function. The rest of the notation is the same as in Equation (1) (see, for example, Olbryś 2019). To provide a suitable choice for the conditional distribution of innovation, the parameters of $\operatorname{GARCH}(\mathrm{p}, \mathrm{q})$ models were estimated via Maximum Likelihood (ML) or Quasi-Maximum Likelihood (QML) methods (Bollerslev and Wooldridge 1992).

\section{Liquidity Measures Utilized in the Research}

Seven liquidity proxies were utilized in the research. Five of them were calculated using high-frequency (intraday) data. These proxies were: Realized Spread (in \%), Price Impact (in \%), Order Ratio (in \%), Relative Spread (in \%), and modified version of the Roll estimator (in \%). Moreover, two liquidity measures were estimated from low-frequency (daily) data. These proxies were: the modified version of the daily Amihud liquidity/illiquidity measure and the modified daily turnover.

\subsection{Liquidity Estimates Calculated Using High-Frequency Data}

The WSE is a pure order-driven stock market with an electronic order book. To estimate various liquidity/illiquidity proxies using intraday data, it is important to recognize the side initiating the transaction. The main goal is to distinguish between buyer- and seller-initiated trades. Information about the best bid and ask price is needed, but unfortunately this information is not publicly available on the WSE. Therefore, researchers have to rely on indirect classification rules to infer the initiator of a trade. Several classification procedures of this type are presented in the literature, but the Lee and Ready (1991) algorithm (LR) remains the most popular. In this study, the LR algorithm is employed, as Olbryś and Mursztyn (2017) confirmed that the LR performs quite well on the WSE for transaction prices and volume records with a time stamp rounded to the nearest second. The empirical results turn out to be robust to the choice of the sample and do not depend on a firm's size.

In this research, five alternative liquidity/illiquidity estimates approximated from intraday data were utilized. Three of them, namely, Realized Spread, Price Impact, and Order Ratio, were supported by a trade side classification procedure (Olbryś and Mursztyn 2017). Moreover, two other proxies based on high-frequency data were used in the study: Relative Spread and the modified version of the Roll (1984) estimator for the effective spread. Table 1 contains definitions of these five liquidity estimates. For all measures, the multiplier 100 converted units to percent.

Table 1. Definitions of liquidity estimates derived from high-frequency data.

\begin{tabular}{|c|c|c|}
\hline & Liquidity Proxy & Definition \\
\hline 1 & Realized Spread (\%) & $\%$ Real $S_{t}=\left\{\begin{array}{l}200 \cdot \ln \frac{P_{t}}{P_{t+5}}, \text { when trade } t \text { is classified as buyer }- \text { initiated } \\
200 \cdot \ln \frac{P_{t+5}}{P_{t}}, \text { when trade } t \text { is classified as seller }- \text { initiated }\end{array}\right.$ \\
\hline 2 & Price Impact (\%) & $\% P I_{t}=\left\{\begin{array}{l}200 \cdot \ln \frac{P_{t+5}^{\text {mid }}}{P_{t}^{\text {mid }}}, \text { when trade } t \text { is classified as buyer }- \text { initiated } \\
200 \cdot \ln \frac{P_{t}^{\text {mid }}}{P_{t+5}^{\text {mid }}}, \text { when trade } t \text { is classified as seller }- \text { initiated }\end{array}\right.$ \\
\hline 3 & Order Ratio (\%) & $\% O R=100 \cdot \frac{\mid \sum_{i=1}^{m} V B u y_{i}-\sum_{j=1}^{k} V \text { Sell }_{j} \mid}{\sum_{n=1}^{N} V_{n}}$ \\
\hline 4 & Relative Spread (\%) & $\% R S_{t}=\frac{200 \cdot\left(P_{t}^{H}-P_{t}^{L}\right)}{P_{t}^{H}+P_{t}^{L}}$ \\
\hline 5 & $\begin{array}{l}\text { The modified version of the Roll } \\
\text { Estimator (\%) }\end{array}$ & MRoll $_{t}=\left\{\begin{array}{c}200 \cdot \sqrt{-\operatorname{cov}\left(R_{t}, R_{t-1}\right)}, \text { when } \operatorname{cov}\left(R_{t}, R_{t-1}\right)<0 \\
0, \text { when } \operatorname{cov}\left(R_{t}, R_{t-1}\right) \geq 0\end{array}\right.$ \\
\hline
\end{tabular}

$P_{t}$ is the transaction price of a stock at time $t$, approximated by the closing price, $P_{t+5}$ is the closing price of the fifth trade after trade $t$ for a stock, $P_{t}^{H}, P_{t}^{L}$ are the high and low prices of a stock at time $t$, respectively, $P_{t}^{\text {mid }}=\frac{P_{t}^{H}+P_{t}^{L}}{2}$ is the midpoint price at time $t$ for a stock, $\sum_{i=1}^{m} V B u y_{i}$ is the aggregated daily volume of transactions classified as buyer-initiated for a stock, $\sum_{j=1}^{k} V$ Sell $_{j}$ is the aggregated daily volume of transactions classified as seller-initiated for a stock, $\sum_{n=1}^{N} V_{n}$ is the aggregated daily volume of all transactions for a stock, $R_{t}$ is the ultra-short logarithmic rate of return of a stock at time $t$. 
Table 1 requires some explanation. Realized Spread is a temporary component of the effective spread, and it is sometimes referred to as a price reversal component, since a dealer makes a profit only if the price reverses (Huang and Stoll 1996). Daily value of this indicator is calculated as a volume-weighted average of realized spreads computed over all trades within a day, and it is defined as equal to zero when all transactions within a day are unclassified.

Price Impact is usually defined as the increase (decrease) in the quote midpoint over a time interval beginning at the time of the buyer-(seller-) initiated trade. This is a permanent component of effective spread (Goyenko et al. 2009). Daily value of the price impact proxy is estimated as a volume-weighted average of price impact proxies computed over all trades within a day. It is defined as equal to zero when all transactions within a day are unclassified.

Order Ratio is used as an indicator of imbalance in daily orders. A low value of this indicator denotes high liquidity. It rises as the difference in the numerator grows. Daily value of this indicator is defined to be equal to zero in the following two cases: (1) when the total volume of daily trading, in the denominator, is equal to zero, or (2) when all of the transactions within a day are unclassified.

Relative Spread is a measure of illiquidity as high value of this indicator denotes low liquidity, while a low value indicates high liquidity. The value of this indicator is equal to zero when the high and low prices of a stock at time $t$ are equal. Daily value of relative spread is computed as a volume-weighted average of relative spreads calculated over all the trades within a day.

The modified version of the Roll estimator for the effective spread is approximated based on trade-to-trade price changes within a day (Stoll 2000). The original version of the Roll estimator is well-defined only for negative first-order serial covariance of price changes, which is not guaranteed in practice. As Corwin and Schultz (2012) emphasized, the serial covariance of price changes is frequently positive and, in such cases, researchers can do one of the following things: (1) set the Roll estimator to zero, (2) treat the observation as missing, or (3) multiply the serial covariance by -1 , calculate the spread, and multiply the spread by -1 to obtain a negative estimate. In this study, the first approach was used (Olbryś and Mursztyn 2019).

\subsection{Liquidity Proxies Calculated Using Low-Frequency Daily Data}

In this research, two liquidity/illiquidity estimates using daily data were calculated: the modified version of the Amihud (2002) illiquidity measure and the modified version of daily turnover. Details are presented in Table 2, but they need some comments.

Table 2. Definition of liquidity estimates derived from low-frequency daily data.

\begin{tabular}{|c|c|c|}
\hline & Liquidity Proxy & Definition \\
\hline 1 & $\begin{array}{l}\text { The modified version of the } \\
\text { Amihud Measure }\end{array}$ & MAmih $_{t}=\left\{\begin{array}{c}\log \left(1+\frac{\left|r_{t}\right|}{V_{t}}\right), \text { when } V_{t} \neq 0 \\
0, \text { when } V_{t}=0\end{array}\right.$ \\
\hline 2 & $\begin{array}{c}\text { The modified version of Daily } \\
\text { Turnover }\end{array}$ & $\begin{aligned} M T_{t}= & \log \left[1+\frac{V_{t}}{N S O_{t}}\right]-\frac{1}{30} \\
& \cdot \sum_{k=1}^{30} \log \left[1+\frac{V_{t-k}}{N S O_{t-k}}\right]\end{aligned}$ \\
\hline
\end{tabular}

$r_{t}$ is the simple rate of return of stock on day $t, V_{t}$ is the trading volume of stock on day $t, \mathrm{NSO}_{t}$ is the number of shares outstanding of stock on day $t$.

In the literature, the Amihud measure is usually calculated monthly or for other periods (Goyenko et al. 2009; Foran et al. 2015; Fong et al. 2017), but in this paper, daily values of this proxy were estimated (Olbryś 2019). The value of the daily Amihud measure was defined to be equal to zero when the total volume of daily trading was equal to zero.

The modified version of daily turnover was computed in logs and de-trended with a 30-day moving average to account for non-stationarity. Our proposition followed Karolyi et al. (2012), however, we used the number of shares outstanding at the beginning of the quarter. The moving average was 
calculated for the available data over the past 30 trading days. It is worth noting that computing the modified version of this indicator disentangled day-of-the-week effects from daily turnover.

\section{Principal Component Analysis}

The Principal Component Analysis (PCA) is the most common factor model. Factor models are employed primarily as dimensionality reduction procedures in the case of a set of closely related variables (Brooks 2019). The PCA is a multivariate non-parametric technique that analyzes a data matrix in which observations are described by several inter-correlated quantitative variables (Abdi and Williams 2010). The main idea is to reduce the dimensionality of a data set containing a large number of interrelated variables, while retaining as much as possible of the variation present in the data. Observable input variables are transformed into new unobservable (latent) variables called principal components. Principal components (PCs) are linear combinations of original variables. Consecutive PCs are uncorrelated with each other and are computed in a way that maximizes variance that has not been explained by preceding PCs. As a consequence, a few first PCs contain the majority of information that is contained in the data set. The PCA constructs common factors to maximize explanatory power within a set of related variables (Hasbrouck and Seppi 2001).

Assume that $X$ is a vector of $N$ random variables, and a correlation (or covariance) matrix $\Omega$ of elements of vector $X$ is known. The first step of the PCA is to find a linear function $\alpha_{1}^{T} x$ of the elements of the vector $X$ (called the first $\mathrm{PC}$ ) having a maximum variance and given by Equation (3):

$$
z_{1}=\alpha_{1}^{T} X=\alpha_{11} x_{1}+\alpha_{12} x_{2}+\cdots+\alpha_{1 N} x_{N}=\sum_{j=1}^{N} \alpha_{1 j} x_{j},
$$

where $\alpha_{1}=\left[\alpha_{11}, \alpha_{12}, \ldots, \alpha_{1 N}\right]^{T}$ is a vector of $N$ factor loadings. The next step is to find a linear function $z_{2}=\alpha_{2}^{T} x$ (called the second PC), which is uncorrelated with $z_{1}$ and has maximum variance. The procedure is then repeated. The $k$-th derived variable is the $k$-th PC and it is given by Equation (4):

$$
z_{k}=\alpha_{k}^{T} X, k=1,2, \ldots, N,
$$

where $\alpha_{k}$ is an eigenvector of $\Omega$ corresponding to its $k$-th largest eigenvalue $\lambda_{k}$. Furthermore, if $\alpha_{k}$ is chosen to have unit length, then $\operatorname{var}\left(z_{k}\right)=\lambda_{k}$ (Jolliffe 2002). The PCs are derived in such a way that they are in descending order of importance. Although there are $k \mathrm{PCs}$, the same as the explanatory variables, it is likely that some of the last few PCs will account for so little of the variation that they can be discarded (Brooks 2019).

What is important is that the PCA is scale-dependent. The PCs of a covariance matrix and those of a correlation matrix are different. In applied research, the PCA of a covariance matrix is useful only if the variables are expressed in commensurable units. When variables are measured along different scales or they differ significantly in terms of variability, it is recommended to calculate the PCs from the sample correlation matrix, which is analogous to standardizing all the variables prior to calculation (Jackson 1991; Jolliffe 2002).

The goal of the PCA is to extract the majority of important information from a data matrix. The question is: how many components need to be considered? One of the standard procedures is the Kaiser (1958) criterion. For the correlation matrix used as input for the PCA, the Kaiser criterion suggests that only the PCs with an eigenvalue larger than unity should be used, as it means that the PCs are larger than the average eigenvalue (Abdi and Williams 2010).

\section{Data Description and Empirical Findings on the Warsaw Stock Exchange}

In our research, two data samples were used. The first sample consisted of daily data, from 2 January 2005 to 30 December 2016, for the group of 86 WSE-traded companies. It contained 3005 trading days for each stock. The second sample contained high-frequency data. This data set included 
transaction prices and volume records with a time stamp rounded to the nearest second for the same period and the same group of equities. Both daily and intraday data sets included the opening, high, low, and closing prices, as well as the volume for each security over one unit of time. The data came from the Bank Ochrony Środowiska (BOS, Bank for Environmental Protection) brokerage house (available at http://bossa.pl). It is worth noting that a large number of the WSE-listed companies revealed a substantial non-trading problem, which affected the database content (Nowak and Olbryś 2016). The non-trading problem meant that stocks exhibited an extraordinary number of non-traded days. Therefore, the 138 WSE companies were initially selected, but to mitigate some serious problems with liquidity, the 86 firms were finally entered into the database. This study is the continuation and extension of the research on commonality in liquidity on the WSE presented in the paper (Olbryś 2019), and therefore the used database is the same.

To verify the stability of the empirical findings, the calculations were conducted both for the whole sample and over three consecutive sub-samples, each of equal length -436 trading days (Olbryś and Mursztyn 2019, p. 185):

1. The pre-crisis sub-period 6 September 2005-31 May 2007,

2. The crisis sub-period on the WSE 1 June 2007-27 February 2009,

3. The post-crisis sub-period 2 March 2009-19 November 2010.

The crisis sub-period on the WSE was formally defined based on the paper (Olbrys and Majewska 2016) in which the crisis periods on the Central and Eastern European (CEE) stock markets were approximated with the use of the Pagan and Sossounov (2003) statistical method of dividing market states.

\subsection{Descriptive Statistics of Liquidity Proxies on the WSE}

The properties of liquidity proxies utilized in this study were thoroughly investigated and presented in the recent papers. Olbrys and Mursztyn $(2018,2019)$ explored basic distributional properties (asymmetry, normality, tail thickness), as well as linear and non-linear dependences, and stationarity of daily time series of seven liquidity proxies that are used in the present paper. The results confirmed some stylized facts and typical features of the analyzed time series.

What is important is that six liquidity proxies used in this study, namely: (1) Relative Spread, (2) Realized Spread, (3) Price Impact, (4) Order Ratio, (5) modified version of the Roll estimator, and (6) modified Amihud measure, approximated illiquidity. Therefore, before the PCA calculations, the series were multiplied by -1 to obtain variables that were increasing alongside liquidity of individual equities. Only the modified version of daily turnover measured liquidity, while the remaining six estimates were transformed into liquidity proxies. In the next step, the aggregate liquidity proxies were calculated as the cross-sectional averages of the corresponding individual stock liquidity measures for the group of 86 companies within the whole sample period. Table 3 reports basic descriptive statistics for seven cross-sectional liquidity proxies.

Table 3. Basic descriptive statistics for cross-section of liquidity proxies within the whole sample period January 2005-December 2016 (3005 trading days for each variable).

\begin{tabular}{cccccc}
\hline & Liquidity Proxy & Mean & Average Std. Dev. & Min. & Max. \\
\hline 1 & \%RealS & -0.2375 & 0.1382 & -1.0490 & 0.3908 \\
2 & \%PI & 0.0874 & 0.0897 & -0.4515 & 0.6592 \\
3 & \%OR & -38.5456 & 3.6578 & -52.3617 & -19.6603 \\
4 & \%RS & -0.1293 & 0.0333 & -0.3190 & -0.0529 \\
5 & MRoll & -0.6754 & 0.1757 & -1.8924 & -0.2663 \\
6 & MAmih & -0.0041 & 0.0063 & -0.0501 & -0.00004 \\
7 & MT & 0.0004 & 0.0004 & -0.0009 & 0.0050 \\
\hline
\end{tabular}

Notes: Liquidity proxies are defined in Tables 1 and 2. "Mean" is the cross-sectional average of the time series averages. "Average Std. Dev." is the cross-sectional standard deviation of the time series means of each measure. 


\subsection{Principal Components of Liquidity on the WSE}

This subsection reports the PCA findings from seven liquidity estimates for the group of 86 companies on the WSE. In the PCA, input liquidity variables were converted into new (latent) uncorrelated liquidity variables called PCs, which are linear combinations of original variables. To get standardized factors, the correlation matrix was used as input for the PCA. There were seven PCs, the same as the explanatory liquidity variables.

Table 4 presents the principal components PC1-PC7 corresponding to the first to smallest eigenvalues, the loadings of the PCs with the respective variance that the corresponding eigenvectors explain, and the cumulative variance explained within the whole sample period. The three eigenvalues that were larger than unity represented more than $66 \%$ of total liquidity variation. According to the Kaiser (1958) criterion, these three PCs were sufficient to substitute for the seven liquidity proxies used in this research.

Table 4. The Principal Component Analysis (PCA) findings from the seven liquidity proxies on the Warsaw Stock Exchange (WSE) (the whole sample period).

\begin{tabular}{ccccccccc}
\hline \multicolumn{1}{c}{ Principal Component Analysis } \\
\hline & Liquidity Proxy & PC1 & PC2 & PC3 & PC4 & PC5 & PC6 & PC7 \\
\hline 1 & \%RealS & 0.661 & 0.204 & -0.005 & -0.018 & -0.056 & 0.130 & -0.708 \\
2 & \%PI & -0.626 & -0.342 & -0.005 & 0.042 & 0.069 & -0.029 & -0.696 \\
3 & \%OR & -0.060 & -0.105 & -0.583 & -0.572 & -0.514 & 0.231 & 0.015 \\
4 & \%RS & 0.235 & -0.662 & -0.045 & 0.186 & 0.240 & 0.631 & 0.122 \\
5 & MRoll & 0.315 & -0.521 & -0.321 & 0.078 & 0.023 & -0.721 & 0.012 \\
6 & MAmih & -0.086 & 0.172 & -0.416 & 0.792 & -0.391 & 0.097 & 0.0003 \\
7 & MT & -0.067 & 0.304 & -0.617 & -0.048 & 0.719 & 0.044 & -0.018 \\
& Eigenvalue & $\mathbf{2 . 0 1 4}$ & $\mathbf{1 . 3 2 6}$ & $\mathbf{1 . 3 0 1}$ & 0.965 & 0.714 & 0.577 & 0.103 \\
\% variance explained & $28.77 \%$ & $18.94 \%$ & $18.59 \%$ & $13.79 \%$ & $10.19 \%$ & $8.24 \%$ & $1.47 \%$ \\
\hline
\end{tabular}

Notes: Liquidity proxies are defined in Tables 1 and 2. PC1-PC7 denote principal components. Eigenvalues larger than unity (PC1-PC3) are marked in bold.

Table 5 reports summarized results of robustness analyses from seven liquidity proxies. It presents principal components PC1-PC7 corresponding to the first to smallest eigenvalues over three consecutive sub-samples: the pre-crisis, crisis, and post-crisis sub-periods. The results were homogenous as the first three eigenvalues (PC1-PC3) were larger than unity in the case of all investigated sub-periods. The cumulative variance explained was almost the same within all considered sub-periods. Specifically, the first three eigenvalues PC1-PC3 represented $67.9 \%$ (the pre-crisis sub-period), $66.9 \%$ (the crisis sub-period), and $68 \%$ (the post-crisis sub-period) of total liquidity variation, respectively. Therefore, based on the Kaiser (1958) criterion, the last four PCs could be discarded.

Table 5. The summarized PCA results from seven liquidity proxies for three sub-periods on the WSE.

\begin{tabular}{cccccccc}
\hline \multicolumn{7}{c}{ Principal Component Analysis } \\
\hline & PC1 & PC2 & PC3 & PC4 & PC5 & PC6 & PC7 \\
\hline & & \multicolumn{7}{c}{ The sub-period S1 } \\
\hline Eigenvalue & $\mathbf{1 . 9 2 0}$ & $\mathbf{1 . 5 0 4}$ & $\mathbf{1 . 3 2 7}$ & 0.960 & 0.765 & 0.454 & 0.071 \\
\% cumulative variance explained & $27.4 \%$ & $48.9 \%$ & $67.9 \%$ & $81.6 \%$ & $92.5 \%$ & $99 \%$ & $100 \%$ \\
\hline & & \multicolumn{7}{c}{ The sub-period S2 } \\
\hline Eigenvalue & $\mathbf{1 . 9 3 5}$ & $\mathbf{1 . 4 2 5}$ & $\mathbf{1 . 3 2 3}$ & 0.902 & 0.690 & 0.626 & 0.098 \\
\% cumulative variance explained & $27.7 \%$ & $48 \%$ & $66.9 \%$ & $79.8 \%$ & $89.7 \%$ & $98.6 \%$ & $100 \%$ \\
\hline & & \multicolumn{7}{c}{ The sub-period S3 } & & \\
\hline Eigenvalue & $\mathbf{2 . 1 0 9}$ & $\mathbf{1 . 6 3 5}$ & $\mathbf{1 . 0 1 9}$ & 0.867 & 0.699 & 0.579 & 0.092 \\
\% cumulative variance explained & $30.1 \%$ & $53.5 \%$ & $68 \%$ & $80.4 \%$ & $90.4 \%$ & $98.7 \%$ & $100 \%$ \\
\hline
\end{tabular}

Notes: Notation as in Table 4. Eigenvalues larger than unity (PC1-PC3) are marked in bold. S1-the pre-crisis sub-period 6 September 2005-31 May 2007. S2 - the crisis sub-period on the WSE 1 June 2007-27 February 2009. S3-the post-crisis sub-period 2 March 2009-19 November 2010. 


\subsection{Assessing Commonality in Liquidity with the PCA on the WSE}

The empirical PCA findings presented in the previous subsection show that first three principal components PC1-PC3 seemed to capture common sources of liquidity variation on the WSE. The findings are robust to the sub-period choice. Therefore, the next step of the research was to assess commonality in liquidity on the WSE with these three principal components of liquidity proxies as latent factors in econometric models (Foran et al. 2015; Korajczyk and Sadka 2008). According to the recent literature, commonality in liquidity on the WSE is rather weak and robust to the choice of a liquidity measure and a sub-sample period (Będowska-Sójka 2019; Olbryś 2019).

In Section 2, the market model of liquidity introduced by Chordia et al. (2000) was described in detail. To investigate commonality in liquidity, three principal components of liquidity proxies PC1, PC2, and PC3 were used as liquidity (latent) variables in models (1) and (2), respectively.

In the first step, the PC1, PC2, and PC3 series were calculated for each stock (258 series in total). Then, we tested with the ADF-Generalized Least Squares (ADF-GLS) test (Elliott et al. 1996) or ADF test (Dickey and Fuller 1981) whether the analyzed daily time series were stationary. We used a maximum lag equal to five and then removed lags until the last one was statistically significant. The unit root hypothesis was rejected at the 5\% significance level for all the time series used in the study. As the number of time series was large (516 series), details are available upon a request.

Thereafter, we "winsorized" the data by using the 1st and 99th percentiles for each time series to prevent possibly spurious outlier effects (Korajczyk and Sadka 2008). Next, we used the linear regression with the HAC covariance matrix estimator to compute the parameters of the model (1). In total, 258 models were estimated. For each stock, daily proportional changes in individual stock PC1-PC3 as liquidity latent variables were regressed in time series on the changes of an equally weighted cross-sectional average of the latent liquidity variable for all stocks in the sample, excluding the dependent variable stock.

For 110 models (comprising 35 models for PC1, 33 models for PC2, and 42 models for PC3), we detected the ARCH effect in residuals. Hence, for those 110 companies and latent liquidity proxies the $\operatorname{GARCH}(\mathrm{p}, \mathrm{q}), \mathrm{p}, \mathrm{q}=1,2$, models were estimated. The number of lags $\mathrm{p}$, $\mathrm{q}$ was selected using the Akaike (AIC) and Schwarz (SC) information criteria. The summarized cross-sectional estimation results of models (1)-(2) are reported in Table 6. This table contains the number of positive, positive significant, negative, and negative significant slope coefficients (at the $10 \%$ significance level) within the whole sample period. One can observe that the regressions provide no evidence of commonality in liquidity on the WSE because positive and statistically significant coefficients rarely appear. For example, the positive and statistically significant concurrent coefficients constituted 5/86, 2/86, and 6/86 of all concurrent coefficients for the PC1, PC2, and PC3 proxies, respectively. The findings regarding the lag and lead coefficients were very similar. Specifically, the positive and statistically significant lag coefficients constituted 4/86, 1/86, and 7/86 of all lag coefficients, while the positive and statistically significant lead coefficients constituted 5/86, 4/86, and 1/86 of all lead coefficients for the PC1, PC2, and PC3 proxies, respectively.

\subsection{Robustness Tests of Commonality in Liquidity on the WSE}

In this subsection, the stability of the empirical results by time periods is investigated as the related literature has indicated that commonality in liquidity tends to vary over time (Karolyi et al. 2012; Olbryś 2019). Robustness tests over three consecutive sub-samples, each of equal length (436 trading days): the pre-crisis, crisis, and post-crisis sub-periods, are provided. We estimated the parameters of the model (1) for each stock and latent liquidity proxy PC1-PC3, within each sub-period. The total number of estimated models was equal to 86 for each sub-period. Summarized robustness findings are reported in Table 7 . These findings revealed that the number of positive and statistically significant slope coefficients was very small in all cases. The results were homogenous for all investigated sub-periods. Therefore, the robustness tests indicated no reason to reject the research hypothesis that there is no pronounced commonality in liquidity on the WSE. 
Table 6. Testing for commonality in liquidity on the WSE within the whole sample period 2 January 2005-30 December 2016 (3005 trading days) with the principal components PC1-PC3 as latent liquidity proxies.

\begin{tabular}{|c|c|c|c|c|c|c|}
\hline & \multicolumn{2}{|r|}{ DPC1 } & \multicolumn{2}{|r|}{ DPC2 } & \multicolumn{2}{|r|}{ DPC3 } \\
\hline & OLS-HAC 51 Models & $\begin{array}{l}\text { GARCH Conditional Mean } \\
\text { Equation } 35 \text { Models } \\
\end{array}$ & OLS-HAC 53 Models & $\begin{array}{l}\text { GARCH Conditional Mean } \\
\text { Equation } 33 \text { Models } \\
\end{array}$ & OLS-HAC 44 Models & $\begin{array}{l}\text { GARCH Conditional Mean } \\
\text { Equation } 42 \text { Models } \\
\end{array}$ \\
\hline \multicolumn{7}{|c|}{ Concurrent $\beta_{i, 0}$} \\
\hline positive & 17 & 10 & 20 & 17 & 15 & 14 \\
\hline positive significant & 3 & 2 & 1 & 1 & 1 & 5 \\
\hline negative & 28 & 20 & 32 & 12 & 26 & 20 \\
\hline negative significant & 3 & 3 & 0 & 3 & 2 & 3 \\
\hline positive significant (all 86 models) & & 5 & & 2 & & 6 \\
\hline \multicolumn{7}{|c|}{$\operatorname{Lag} \beta_{i,-1}$} \\
\hline positive & 27 & 18 & 26 & 22 & 23 & 15 \\
\hline positive significant & 3 & 1 & 1 & 0 & 1 & 6 \\
\hline negative & 19 & 16 & 23 & 10 & 18 & 18 \\
\hline negative significant & 2 & 0 & 3 & 1 & 2 & 3 \\
\hline positive significant (all 86 models) & & 4 & & 1 & & 7 \\
\hline \multicolumn{7}{|c|}{ Lead $\beta_{i,+1}$} \\
\hline positive & 25 & 18 & 26 & 13 & 21 & 20 \\
\hline positive significant & 4 & 1 & 3 & 1 & 0 & 1 \\
\hline negative & 21 & 15 & 24 & 18 & 21 & 19 \\
\hline negative significant & 1 & 1 & 0 & 1 & 2 & 2 \\
\hline positive significant (all 86 models) & & 5 & & 4 & & 1 \\
\hline
\end{tabular}

Notes: PC1, PC2, and PC3 are three principal components of liquidity proxies. " $\mathrm{D}$ " preceding the acronym denotes a proportional change in the variable across successive trading days. The most important number of positive significant coefficients is marked in bold. 
Table 7. The robustness tests for market-wide commonality in liquidity on the WSE over three consecutive sub-periods S1, S2, and S3.

\begin{tabular}{cccc}
\hline \multirow{2}{*}{ Coefficient } & \multicolumn{2}{c}{ The Number of Positive and Statistically Significant Coefficients } \\
\cline { 2 - 4 } & The Sub-Period S1 & The Sub-Period S2 & The Sub-Period S3 \\
\hline Concurrent $\beta_{i, 0}$ & 8 & DPC1 & \\
Lag $\beta_{i,-1}$ & 5 & 3 & 6 \\
Lead $\beta_{i,+1}$ & 5 & 5 & 7 \\
\hline Concurrent $\beta_{i, 0}$ & & DPC2 & 5 \\
Lag $\beta_{i,-1}$ & 6 & 4 & 4 \\
Lead $\beta_{i,+1}$ & 10 & 0 & 6 \\
\hline & 6 & 6 & \\
\hline Concurrent $\beta_{i, 0}$ & & DPC3 & 6 \\
Lag $\beta_{i,-1}$ & 7 & 5 & 5 \\
Lead $\beta_{i,+1}$ & 9 & 5 & 2 \\
\hline
\end{tabular}

Notes: Notation as in Tables 5 and 6.

The aforementioned empirical results are in accordance with the robustness check findings presented in the paper (Olbryś 2019), in which the rolling window approach was employed to test the stability of the results of model (1) estimation for particular liquidity proxies on the WSE.

\section{Discussion}

The purpose of this paper was to assess market-wide commonality in liquidity on the WSE using the PCA to extract common components of liquidity across a sample of equities, and from a set of liquidity proxies. Seven liquidity estimates were utilized. The empirical PCA findings revealed that the first three principal components PC1-PC3 captured common sources of liquidity variation on the WSE. The results are robust to the sub-period choice.

To infer the patterns of commonality in liquidity, the linear regression with the HAC covariance matrix estimation and the GARCH-type latent factor models of liquidity were employed. The regressions provided no evidence of commonality in liquidity on the WSE because positive and statistically significant coefficients rarely appeared. Robustness tests over three consecutive sub-samples indicated that the findings were homogenous for all investigated sub-periods. Therefore, no reason was found to reject the research hypothesis that commonality in liquidity does not exist on the WSE. Our results are consistent with the recent literature (Będowska-Sójka 2019; Olbryś 2019) and definitely confirm that commonality in liquidity on the WSE is very weak and the results are robust to the choice of a liquidity proxy and investigated sub-period.

However, the recent extensive empirical findings regarding co-movements in liquidity on other equity markets in the world are not homogenous. Apart from a particular stock market size, diverse trading mechanisms and a stock market structure may affect a level of commonality in liquidity on individual developed and emerging equity markets. The literature related to this topic is too vast to give a full list of references. Among others, Korajczyk and Sadka (2008) and Kang and Zhang (2013) investigated and documented an existence of common factors in liquidity on the New York Stock Exchange (NYSE), but the findings on the U.S. equity market are not comparable to those obtained on the WSE for many reasons. As for the stock market design, the WSE is a pure order-driven market, while the American stock exchanges are hybrid markets. Wang (2013) examined 12 equity Asian markets, and the results indicated that liquidity variations on these markets were driven by the common factors. Foran et al. (2015) assessed commonality in liquidity on the U.K. stock exchange and they emphasized that different market structures in the U.K and U.S. exchanges led to crucial differences in liquidity on both markets. Narayan et al. (2015) examined several research hypotheses 
concerning commonality in liquidity on Chinese stock markets, and they found a strong support for co-movements in liquidity on these markets. Bai and Qin (2015) analyzed 18 emerging markets and their results revealed that commonality in liquidity had a geographic component. The authors found that investigated emerging markets in general displayed low liquidity and rather high commonality in liquidity. Sensoy (2016) documented that the U.S. monetary policy and macroeconomic announcements affected commonality in liquidity on the Turkish stock market. Syamala et al. (2017) investigated a pure order-driven emerging market in India, and they discerned determinants of commonality in liquidity on this market. Hadhri and Ftiti (2019) studied 11 emerging markets from the Middle East and North Africa. They concluded that an opportunity for portfolio risk diversification existed as these markets exhibited weak commonality in liquidity. Olbryś (2020) obtained very similar conclusions regarding a possibility of portfolio risk diversification on six small Central and Eastern European stock exchanges that was caused by the lack of liquidity co-movements on these markets.

\section{Conclusions}

The empirical findings of this study may be helpful in decision-making processes on financial markets. From an investor's point of view, the problem is important since the absence of market-wide liquidity co-movements affects various investment fields. According to the literature, portfolio management and investment strategies, portfolio risk diversification, asset pricing, etc., are influenced by commonality in liquidity effects. Moreover, general results regarding liquidity are crucial as they could help policy makers and regulators in improving financial market design.

A possible direction for further research could be a comparative investigation of commonality in liquidity on other Central and Eastern European (CEE) stock exchanges using the PCA to extract common factors from liquidity measures. To the authors' knowledge, no analogical study has been presented in the literature so far. However, there are several limitations on such research. First of all, the main empirical problem is that these markets are extremely illiquid. As a consequence, the data should be filtered out, and the reduction of the number of companies that could be contained in the database would be crucial (Olbryś 2020). Moreover, a high-frequency intraday data access is very limited on these emerging markets.

Author Contributions: Conceptualization, J.O.; methodology, J.O.; software, J.O. and E.M.; validation, J.O. and E.M.; formal analysis, J.O. and E.M.; investigation, J.O. and E.M.; resources, J.O. and E.M.; data curation, J.O. and E.M.; writing — original draft preparation, J.O.; writing—review and editing, J.O.; supervision, J.O.; project administration, J.O. All authors have read and agreed to the published version of the manuscript.

Funding: The contribution of the first named author was supported by the grant from the National Science Centre, Poland, No. 2016/21/B/HS4/02004.

Conflicts of Interest: The authors declare no conflict of interest.

\section{References}

Abdi, Herve, and Lynne J. Williams. 2010. Principal Component Analysis. Wiley Interdisciplinary Reviews: Computational Analysis 2: 433-59. [CrossRef]

Amihud, Yakov. 2002. Illiquidity and stock returns: Cross-section and time-series effects. Journal of Financial Markets 5: 31-56. [CrossRef]

Bai, Min, and Yafeng Qin. 2015. Commonality in liquidity in emerging markets: Another supply-side explanation. International Review of Economics and Finance 39: 90-106. [CrossRef]

Będowska-Sójka, Barbara. 2019. Commonality in liquidity measures. The evidence from the Polish stock market. Hradec Economic Days 9: 29-40.

Bollerslev, Tim, and Jeffrey M. Wooldridge. 1992. Quasi-maximum likelihood estimation and inference in dynamic models with time-varying covariances. Econometric Reviews 11. [CrossRef]

Brockman, Paul, Dennis Y. Chung, and Christophe Perignon. 2009. Commonality in liquidity: A global perspective. Journal of Financial and Quantitative Analysis 44: 851-82. [CrossRef]

Brooks, Chris. 2019. Introductory Econometrics for Finance, 4th ed. Cambridge: Cambridge University Press. 
Chen, Jing. 2005. Pervasive Liquidity risk and Asset Pricing. Job Market Paper. New York: Columbia University.

Chordia, Tarun, Richard Roll, and Avanidhar Subrahmanyam. 2000. Commonality in liquidity. Journal of Financial Economics 56: 3-28. [CrossRef]

Corwin, Shane A., and Paul Schultz. 2012. A simply way to estimate bid-ask spreads from daily high and low prices. Journal of Finance 67: 719-59. [CrossRef]

Dickey, David A., and Wayne A. Fuller. 1981. Likelihood ratio statistics for autoregressive time series with a unit root. Econometrica 49: 1057-72. [CrossRef]

Dimson, Elroy. 1979. Risk measurement when shares are subject to infrequent trading. Journal of Financial Economics 7: 197-226. [CrossRef]

Elliott, Graham, Thomas J. Rothenberg, and James H. Stock. 1996. Efficient tests for an autoregressive unit root. Econometrica 64: 813-36. [CrossRef]

Engle, Robert F. 1982. Autoregressive conditional heteroscedasticity with estimates of the variance of United Kingdom inflations. Econometrica 50: 987-1007. [CrossRef]

Fong, Kingsley Y. L., Craig W. Holden, and Charles A. Trzcinka. 2017. What are the best liquidity proxies for global research? Review of Finance 21: 1355-401. [CrossRef]

Foran, Jason, Mark C. Hutchinson, and Niall O'Sullivan. 2015. Liquidity commonality and pricing in UK. Research in International Business and Finance 34: 281-93. [CrossRef]

Goyenko, Ruslan, Craig W. Holden, and Charles A. Trzcinka. 2009. Do liquidity measures measure liquidity? Journal of Financial Economics 92: 153-81. [CrossRef]

Hadhri, Sinda, and Zied Ftiti. 2019. Commonality in liquidity among Middle East and North Africa emerging stock markets: Does it really matter? Economic Systems 43: 100699. [CrossRef]

Harris, Larry. 2003. Trading and Exchanges: Market Microstructure for Practitioners. Oxford: Oxford University Press.

Hasbrouck, Joel, and Duane J. Seppi. 2001. Common factors in prices, order flows, and liquidity. Journal of Financial Economics 59: 383-411. [CrossRef]

Huang, Roger D., and Hans S. Stoll. 1996. Dealer versus auction markets: A paired comparison of execution costs on NASDAQ and the NYSE. Journal of Financial Economics 41: 313-57. [CrossRef]

Jackson, J. Edward. 1991. A User's Guide to Principal Components. New York: Wiley.

Jolliffe, Ian T. 2002. Principal Component Analysis, 2nd ed. Springer Series in Statistics; New York: Springer.

Kaiser, Henry F. 1958. The varimax criterion for analytic rotation in factor analysis. Psychometrika 23: 187-200. [CrossRef]

Kang, Wenjin, and Huiping Zhang. 2013. Limit order book and commonality in liquidity. Financial Review 48: 97-122. [CrossRef]

Karolyi, G. Andrew, Kuan-Hui Lee, and Mathijs A. van Dijk. 2012. Understanding commonality in liquidity around the world. Journal of Financial Economics 105: 82-112. [CrossRef]

Korajczyk, Robert A., and Ronnie Sadka. 2008. Pricing the commonality across alternative measures of liquidity. Journal of Financial Economics 87: 45-72. [CrossRef]

Lee, Charles M. C., and Mark J. Ready. 1991. Inferring trade direction from intraday data. Journal of Finance 46: 733-46. [CrossRef]

Madhavan, Ananth. 2000. Market microstructure: A survey. Journal of Financial Markets 3: 205-58. [CrossRef]

Narayan, Paresh Kumar, Zhichao Zhang, and Xinwei Zheng. 2015. Some hypotheses on commonality in liquidity: New evidence from the Chinese stock market. Emerging Markets Finance and Trade 51: 915-44. [CrossRef]

Newey, Whitney K., and Kenneth D. West. 1987. A simple, positive semi-define, heteroskesticity and autocorrelation consistent covariance matrix. Econometrica 55: 703-8. [CrossRef]

Nowak, Sabina, and Joanna Olbryś. 2016. Direct evidence of non-trading on the Warsaw Stock Exchange. Research Papers of Wroclaw University of Economics 428: 184-94. [CrossRef]

Olbryś, Joanna. 2019. Intra-market commonality in liquidity. New evidence from the Polish stock exchange. Equilibrium. Quarterly Journal of Economics and Economic Policy 14: 251-75. [CrossRef]

Olbryś, Joanna. 2020. No commonality in liquidity on small emerging markets? Evidence from the Central and Eastern European stock exchanges. Comparative Economic Research. Central and Eastern Europe 23: 91-109. [CrossRef]

Olbrys, Joanna, and Elzbieta Majewska. 2016. Crisis periods and contagion effects in the CEE stock markets: The influence of the 2007 U.S. subprime crisis. International Journal of Computational Economics and Econometrics 6: 124-37. [CrossRef] 
Olbryś, Joanna, and Michał Mursztyn. 2017. Measurement of stock market liquidity supported by an algorithm inferring the initiator of a trade. Operations Research and Decisions 27: 111-27. [CrossRef]

Olbrys, Joanna, and Michal Mursztyn. 2018. On some characteristics of liquidity proxy time series. Evidence from the Polish stock market. In Advances in Time Series Data Methods in Applied Economic Research. Springer Proceedings in Business and Economics. Edited by Nicholas Tsounis and Aspasia Vlachvei. Cham: Springer, pp. 177-89. [CrossRef]

Olbryś, Joanna, and Michał Mursztyn. 2019. Alternative estimators for the effective spread derived from high-frequency data. In Effective Investment on Capital Market. Springer Proceedings in Business and Economics. Edited by Waldemar Tarczyński and Kesra Nermend. Cham: Springer, pp. 177-88. [CrossRef]

Pagan, Adrian R., and Kirill A. Sossounov. 2003. A simple framework for analysing bull and bear markets. Journal of Applied Econometrics 18: 23-46. [CrossRef]

Roll, Richard. 1984. A simple implicit measure of the effective bid-ask spread in an efficient market. Journal of Finance 39: 1127-40. [CrossRef]

Sensoy, Ahmed. 2016. Commonality in Liquidity: Effects of Monetary Policy and Macroeconomic Announcements. Finance Research Letters 16: 125-31. [CrossRef]

Stoll, Hans S. 2000. Friction. Journal of Finance 55: 1479-514. [CrossRef]

Syamala, Sudhakara Reddy, Kavita Wadhwa, and Abhinav Goyal. 2017. Determinants of commonality in liquidity: Evidence from an order-driven emerging market. North American Journal of Economics and Finance 42: 38-52. [CrossRef]

Wang, Jianxin. 2013. Liquidity Commonality Among Asian Equity Markets. Pacific-Basin Finance Journal 21: 1209-31. [CrossRef]

Publisher's Note: MDPI stays neutral with regard to jurisdictional claims in published maps and institutional affiliations. 